\title{
Mengukur Tingkat Kepercayaan Muzakki kepada Baitul Mal Aceh
}

\author{
Muhammad Haris Riyaldi, Mahda Yusra \\ Universitas Syiah Kuala Banda Aceh \\ Jl. Teuku Nyak Arief, Kopelma, Darussalam, Kota Banda Aceh, Aceh \\ Email: harisriyaldi@unsyiah.ac.id
}

Diterima: 7 Juni 2020; Direview: 10 Juli 2020; Diterbitkan: 10 Juli 2020

\begin{abstract}
Abstrak,
Kepercayaan merupakan aspek yang penting dibangun di antara muzakki dan lembaga pengelola zakat dalam mengoptimalkan penghimpunan zakat. Penelitian ini mengukur tingkat kepercayaan muzakki kepada Baitul Mal Aceh sebagai lembaga pemerintah yang mengelola zakat di Aceh dengan menggunakan metode deskriptif kuantitatif. Data diperoleh dari muzakki yang membayar zakat di Baitul Mal Aceh dengan kuesioner yang dibagikan kepada 100 orang muzakki yang dipilih berdasarkan teknik persampelan acak sederhana. Hasil penelitian menunjukkan bahwa tingkat kepercayaan muzakki kepada Baitul Mal Aceh tergolong sudah baik. Persepsi muzakki menunjukkan kecenderungan positif mengenai pengelolaan zakat di Baitul Mal Aceh. Diharapkan Baitul Mal Aceh untuk mempertahankan kepercayaan para muzakki sehingga dapat mengoptimalkan penghimpunan zakat di Aceh.
\end{abstract}

Kata kunci: Kepercayaan, Muzakki, Baitul Mal Aceh

\section{Abstract,}

Trust is an important aspect built between muzakki and zakat management institutions in optimizing zakat collection. This study analyzes the level of muzakki's trust in Baitul Mal Aceh as a government agency that manages zakat in Aceh using quantitative descriptive methods. Data was obtained from muzakki who paid zakat at Baitul Mal Aceh with a questionnaire distributed to 100 muzakki who were selected based on a simple random sampling technique. The results showed that the level of muzakki's trust in Baitul Mal Aceh was classified as good. Muzakki's perception shows a positive tendency regarding zakat management in Baitul Mal Aceh. It is hoped that Baitul Mal Aceh will maintain the trust of the muzakki so that it can optimize the collection of zakat in Aceh.

Keywords: Trust, Muzakki, Baitul Mal Aceh 


\section{PENDAHULUAN}

Zakat memiliki peran yang strategis dalam kehidupan umat Islam. Selain sebagai metode membersihkan harta bagi para pembayar zakat (muzakki), zakat juga menjadi instrumen untuk menyejahterakan masyarakat. Fungsi zakat yang strategis ini dapat dicapai apabila pengelolaan zakat dilakukan dengan cakap dan profesional oleh amil zakat. Amil zakat berperan dalam menghimpun zakat dari para muzakki dan kemudian mendistribusikannya kepada golongan masyarakat yang berhak menerimanya.

Di dalam al-Qur'an pada surah al-Taubah ayat ke-103 terdapat perintah agar zakat dikumpulkan dari kaum muslimin. Allah SWT berfirman: "Ambillah zakat dari sebagian harta mereka, dengan zakat itu kami membersihkan dan menyucikan mereka, dan mendoalah untuk mereka. Sesungguhnya doa kamu itu menjadi ketenteraman jiwa bagi mereka. Dan Allah Maha Mendengar lagi Maha Mengetahui." Kandungan ayat ini menjelaskan bahwa Allah SWT memerintahkan Nabi Muhammad SAW sebagai kepala negara dan seorang Nabi untuk menghimpun zakat dari sebagian harta masyarakat muslim (Suma, 2013). Setelah Nabi wafat, maka perintah ini dijalankan oleh para khulafa' arrasyidin dan seterusnya pejabat yang menjadi pemimpin kaum muslimin untuk menjalankan tugas mengelola zakat.

Hafidhuddin (2011) menjelaskan bahwa pada awal masuk dan berkembangnya Islam di Indonesia, pengelolaan zakat dilakukan secara individu maupun kelompok masyarakat. Kemudian, mayoritas ulama di dunia termasuk di Indonesia menyepakati bahwa idealnya tanggung jawab pengelolaan zakat dilakukan oleh pemerintah, dengan harapan pengelolaan yang dilakukan oleh lembaga formal di bawah pemerintah mampu mengoptimalkan pengumpulan dan pengalokasian dana zakat secara efisien dan efektif.

Salah satu provinsi di Indonesia yang menjalankan pengelolaan zakat melalui lembaga yang dibentuk oleh pemerintah yaitu provinsi Aceh. Pengelolaan zakat di Aceh dilaksanakan secara khusus oleh lembaga yang bernama Baitul Mal berdasarkan qanun No.10 tahun 2007 yang merupakan turunan dari Undang-Undang Pemerintah Aceh. Di dalam pasal 3 ayat 1 qanun tersebut dinyatakan bahwa Baitul Mal Aceh merupakan lembaga daerah nonstruktural dalam pemerintahan Aceh. Dalam melaksanakan tugasnya Baitul Mal bersifat independen berdasarkan kepada ketentuan syariat dan bertanggung jawab kepada Gubernur Aceh.

Pada tahun 2018 dikeluarkan Qanun No. 10 Tahun 2018 sebagai pengganti Qanun Nomor 10 Tahun 2007 tentang Baitul Mal. Secara umum, qanun ini tidak mengubah fungsi dan kewenangan Baitul Mal sebagai lembaga yang mengelola zakat di Aceh, demikian juga mengenai muzakki yang diwajibkan untuk membayar zakat di Baitul Mal. Di dalam pasal 
102 Qanun tersebut dinyatakan bahwa: "Muzakki ialah setiap orang yang beragama Islam atau Badan Usaha yang dimiliki oleh orang Islam dan berdomisili dan/atau melakukan kegiatan usaha di Aceh yang memenuhi syarat sebagai Muzakki wajib menunaikan Zakat melalui Baitul Mal”. Namun lahirnya Qanun 10 Tahun 2018 semakin mempertegas wewenang pemerintah Aceh melalui Baitul Mal Aceh untuk mengelola zakat di Aceh dan Baitul Mal Aceh menjadi institusi resmi yang mengelola zakat di Aceh.

Tabel 1. Jumlah Muzakki Baitul Mal Aceh Tahun 2016 - 2018

\begin{tabular}{ccccc}
\hline Tahun & $\begin{array}{c}\text { Muzakki } \\
\text { Individu }\end{array}$ & UPZ & $\begin{array}{c}\text { Muzakki } \\
\text { melalui UPZ }\end{array}$ & $\begin{array}{c}\text { Zakat Terhimpun } \\
\text { (Rp) }\end{array}$ \\
\hline 2015 & 363 & 58 & 5.798 & 27.312 .498 .281 \\
\hline 2016 & 415 & 77 & 9.113 & 27.970 .836 .358 \\
\hline 2017 & 444 & 34 & 23.140 & 53.427 .890 .289 \\
\hline 2018 & 77 & 57 & 22.265 & 54.014 .187 .358 \\
\hline
\end{tabular}

Sumber: Directory Baitul Mal Aceh, 2016-2017

Tabel 1 memperlihatkan peningkatan jumlah muzakki di Baitul Mal Aceh sejak tahun 2015 sampai dengan 2017. Bahkan pada tahun 2017 peningkatan muzakki sangat signifikan, terutama muzakki yang membayar zakat melalui UPZ. Namun pada tahun 2018 terjadi sedikit penurunan jumlah muzakki dari 23140 orang menjadi 22.265 orang. Walaupun demikian dana zakat yang terhimpun pada tahun 2018 terjadi peningkatan. Secara umum sejak 3 tahun terakhir jumlah muzakki Baitul Mal Aceh terus bertambah. Ini merupakan hal positif yang menggambarkan kondisi pengelolaan zakat.

Pengelolaan zakat di Baitul Mal Aceh diakui sudah sangat baik. Pada tahun 2015 Baitul Mal Aceh memperoleh penghargaan nasional dari Kementerian Agama Republik Indonesia pada Zakat Award untuk kategori Manajemen Kelembagaan Zakat terbaik se-Indonesia. Kemudian pada tahun 2018 Baitul Mal Aceh kembali mendapatkan penghargaan sebagai BAZNAS provinsi terbaik se-Indonesia. Dua penghargaan tersebut membuktikan bahwa Baitul Mal Aceh layak dikatakan sebagai lembaga yang mengelola zakat secara profesional.

Walaupun telah mendapat penghargaan, sebagian masyarakat masih menganggap bahwa Baitul Mal sebagai lembaga zakat pemerintah tidak dapat diandalkan. Kurangnya kepercayaan masyarakat kepada lembaga zakat apalagi milik pemerintah disebabkan oleh perilaku sebagian oknum pemerintah yang selama ini terkesan adanya budaya korup dalam mengelola dana publik (Armiadi,2008). Akhirnya mereka menyalurkan zakat bukan kepada lembaga zakat, tetapi kepada para tokoh-tokoh agama ataupun secara langsung kepada 
orang-orang yang dianggap berhak menerima zakat (mustahik). Sebagian masyarakat memilih untuk membayar zakat melalui lembaga zakat swasta (LAZ) karena dianggap lebih akuntabel dan profesional. Hal ini juga berlaku di sebagian wilayah Aceh, terutama di wilayah yang jauh dari jangkauan lembaga pengelola zakat pemerintah.

Namun, sejak lahirnya Qanun terkait pengelolaan zakat dan Baitul Mal di Aceh, jumlah muzakki di Baitul Mal Aceh (BMA) semakin meningkat. BMA terus melakukan sosialisasi pentingnya menunaikan zakat bagi masyarakat, terutama mereka yang memiliki penghasilan mencapai nishab zakat (muzakki). Sebagian besar muzakki tersebut ialah aparatur sipil di instansi pemerintah, baik pada tingkat pusat maupun daerah yang terdapat di provinsi Aceh. Selain itu, TNI, POLRI dan para pegawai Badan Usaha Milik Negara (BUMN) juga menjadi muzakki BMA. Dapat dikatakan bahwa para muzakki di Baitul Mal Aceh membayar zakat karena telah terikat dengan regulasi yang diberlakukan di Aceh. Regulasi mengharuskan pendapatan mereka yang telah mencapai nishab zakat dipotong sejumlah 2,5 persen oleh Unit Pengumpul Zakat (UPZ) yang dibentuk oleh masing-masing instansi. Kemudian UPZ tersebut menyetorkan zakat yang terkumpul ke Baitul Mal Aceh. Sebagian lainnya merupakan muzakki individu yang menyerahkan zakatnya secara langsung ke Baitul Mal Aceh tanpa melalui UPZ. Jumlah muzakki individu juga terus mengalami peningkatan. Hal ini menunjukkan tingkat kepercayaan mereka yang semakin baik.

Sejauh penelusuran penulis, kajian yang mengangkat tingkat kepercayaan muzkki kepada institusi zakat telah dilakukan oleh Inayah (2018), Hasrina, Yusri dan Agusti (2018), Ghazali (2016) dan Nasim dan Romdhon (2014). Mereka meneliti variabel kepercayaan muzakki dalam kaitan dengan variabel penelitian lainnya. Inayah (2018) meneliti kepercayaan yang berpengaruh kepada loyalitas muzakki. Sedangkan Hasrina, Yusri dan Agusti (2018), Ghazali (2016) dan Nasim dan Romdhon (2014) meneliti faktor-faktor yang mempengaruhi kepercayaan muzakki. Namun belum ditemukan kajian yang menganalisis tingkat kepercayaan muzakki kepada Baitul Mal Aceh. Sedangkan kepercayaan merupakan salah satu hal positif yang perlu dibangun diantara muzakki dan institusi zakat dalam upaya optimalisasi pengumpulan zakat (Zainal, 2016). Dalam bidang ekonomi dan bisnis, kepercayaan adalah katalis dalam transaksi antara penjual dan pembeli untuk mewujudkan kepuasan konsumen (Yousafzai, 2003)

Artikel ini menganalisis tingkat kepercayaan muzakki kepada Baitul Mal sebagai lembaga yang mengelola zakat sehingga dapat tergambar tingkat kepercayaan mereka kepada Baitul Mal Aceh sudah baik atau belum. Pada bagian awal artikel ini diuraikan latar belakang permasalahan. Selanjutnya diuraikan tinjauan literatur mengenai konsep lembaga pengelola zakat dan kepercayaan muzakki. Bagian selanjutnya metode penelitian, penyajian hasil penelitian dan pada bagian akhir yaitu kesimpulan dan saran. 


\section{TINJAUAN TEORITIK}

\section{Lembaga Pengelola Zakat}

Keberadaan lembaga pengelola zakat tidak terlepas dari adanya 'amil sebagai penanggung jawab zakat. Disebabkan pentingnya zakat bagi perwujudan hidup bermasyarakat, maka Nabi Muhammad SAW membentuk badan 'amalah (lembaga amil) untuk mengumpulkan zakat dan membagikannya kepada golongan yang berhak menerimanya (Ash-Shiddieqy, 2009). Syariat Islam menetapkan ketentuan standar bagi orang-orang yang diamanahkan menjadi amil zakat. Ketentuan tersebut yaitu harus beragama Islam, sudah mencapai aqil baligh memiliki ilmu dalam hukum zakat, jujur, dan harus orang yang kuat jiwa maupun raga (Luthfi, 2018). Nabi Muhammad SAW pernah menugaskan Ibnu Lutaibah, seorang pemuda dari Bani Asad, untuk mengurus zakat Bani Sulaim. Beliau juga pernah mengutus Ali bin Abi Thalib dan Muadz bin Jabal ke Yaman untuk bertugas sebagai amil. Dan pada masa khulafaurrasyidin, para khalifah juga membentuk badan 'amalah yang memiliki petugas khusus untuk mengelola zakat, baik menghimpun maupun mendistribusikannya. Hal inilah yang menjadi dasar pada masa sekarang pengelolaan zakat diatur oleh pemerintah (Hafidhuddin, 2011)

Di Indonesia, perhatian pemerintah dalam pengelolaan zakat dimulai pada tahun 1968. Pemerintah membentuk Badan Amil Zakat, Infak dan Sedekah (BAZIS) yang berperan memaksimalkan fungsi zakat bagi kesejahteraan umat. Pada tahun inilah awal mula pengelolaan zakat masuk dalam ranah pemerintahan. Selanjutnya pada tahun 1999 lahirlah Undang-Undang (UU) No.38 tentang pengelolaan zakat dan pada tahun 2011 regulasi ini disempurnakan dengan dikeluarkannya Undang-Undang No.23 tahun 2011 tentang pengelolaan zakat.

Di dalam Bab II pasal 5 ayat 1 UU No. 23 Tahun 2011 dinyatakan bahwa dalam menjalankan pengelolaan zakat di Indonesia, pemerintah membentuk Badan Amil Zakat Nasional (BAZNAS). Dalam upaya memudahkan tata kelola zakat, maka dalam pasal 16 diamanahkan bahwa BAZNAS pada tingkat pusat, provinsi dan Kabupaten/Kota dapat membentuk Unit Pengumpul Zakat (UPZ), baik pada instansi pemerintah, badan usaha milik negara, badan usaha milik daerah, perusahaan swasta, dan perwakilan Republik Indonesia di luar negeri serta maupun UPZ pada tingkat kecamatan, kelurahan atau nama lainnya, dan tempat lainnya.

Walaupun demikian, peran pengelolaan zakat oleh masyarakat juga tetap diakomodir dalam UU tersebut. Di dalam pasal 17 dinyatakan peran masyarakat untuk membentuk Lembaga Amil Zakat (LAZ). Keberadaannya LAZ diharapakan dapat membantu BAZNAS, baik dalam pengumpulan, pendistribusian, maupun pendayagunaan zakat. 
Kedua jenis lembaga zakat, baik BAZNAS maupun LAZ beroperasi di hampir seluruh provinsi di Indonesia. Namun, sebagai salah satu provinsi yang memiliki otonomi khusus, lembaga zakat yang dibentuk oleh pemerintah disebut dengan Baitul Mal. Keberadaan Baitul Mal sebagai organisasi pengelola zakat dinyatakan dalam Qanun No.10 tahun 2018. Di dalam Qanun ini dinyatakan bahwa Baitul Mal adalah lembaga keistimewaan dan kekhususan pada Pemerintah Aceh dan Pemerintah Kabupaten/Kota di Aceh. Dalam menjalankan tugas Baitul Mal bersifat independen dan memiliki kewenangan untuk menjaga, mengelola dan mengembangkan zakat, infak, harta wakaf, dan harta keagamaan lainnya berdasarkan syariat Islam.

\section{Konsep Muzakki}

Muzakki merupakan bagian yang sangat penting dalam pelaksanaan perintah wajib zakat. Kesadaran muzakki untuk mengeluarkan bagian tertentu dari harta kekayaannya adalah hal yang perlu serius diberi perhatian oleh lembaga pengelola zakat. Salah satu indikator keberhasilan lembaga pengelola zakat ditentukan oleh kemampuan menghimpun muzakki. Ramainya muzakki merupakan salah satu indikator baiknya kinerja suatu lembaga zakat, karena dana zakat dari para muzakki inilah yang didistribusikan kepada mustahiq dalam rangka memperbaiki ekonomi umat (Rais, 2009).

Syariat Islam menempatkan zakat pada salah satu kewajiban dasar dalam agama. Seorang muslim yang menunaikan zakat (disebut muzakki), maka ia telah membuktikan pengabdian (ibadah) dalam dimensi hubungan hamba dengan Allah SWT, dan sekaligus hubungan yang baik dengan sesama manusia. Hal ini disebabkan dampak zakat bukan hanya bagi orang yang menunaikan zakat, tetapi berdampak juga membantu aspek sosial dan ekonomi para penerima zakat. Zakat yang dibagikan kepada ashnaf fakir dan miskin dapat meringankan beban perekonomian mereka, sekaligus memelihara hubungan baik antara fakir miskin dan para pemilik harta yang mengeluarkan zakat (Riyaldi, 2017).

Di dalam tinjauan ilmu fiqh, seorang muzakki berarti seorang Muslim yang diberikan harta oleh Allah SWT dan telah memenuhi syarat sehingga dirinya wajib menginfakkan sebahagian hartanya kepada golongan tertentu yang berhak menerimanya. Selain sebagai muslim yang memiliki kekayaan dalam jumlah tertentu, zakat diwajibkan kepada seorang yang merdeka, dewasa dan berakal sehat (Rais, 2009).

Persepsi muzakki mengenai kredibilitas lembaga zakat adalah salah satu faktor penentu preferensi mereka untuk memilih lembaga zakat. Kredibilitas menunjukkan profesionalitas lembaga pengelola zakat dalam melaksanakan sistem pengelolaan zakat. Jika muzakki memiliki kepercayaan kepada pengelola zakat, maka muzakki akan menyerahkan zakatnya kepada lembaga tersebut (Ma'fiyah, 2018). 


\section{Kepercayaan Muzakki}

Dalam sistem pengelolaan zakat, kepercayaan muzakki merupakan aspek yang vital bagi lembaga pengelola zakat. Perilaku muzakki dalam membayar zakat sangat bergantung kepada kepercayaan mereka kepada lembaga zakat. Tidak ada kepercayaan merupakan salah satu penghalang bagi muzakki untuk membayarkan zakatnya melalui lembaga zakat. Akibatnya sebagian mereka memilih memberikan zakatnya secara langsung kepada mustahik. Oleh karena itu, pemahaman terhadap perilaku kepatuhan membayar zakat sangat penting bagi lembaga pengelola zakat dalam rangka optimalisasi penghimpunan dana zakat (Mustafa, 2013).

Kepercayaan merupakan bentuk penilaian atas kredibilitas pihak yang diberi amanah atas kemampuannya dalam menyelesaikan tugas dan tanggungjawabnya (Inayah, 2018). Kepercayaan muzakki kepada lembaga zakat merupakan penilaian muzakki atas kemampuan lembaga pengelola zakat dalam menjalankan tanggung jawabnya. Inayah (2018) menyatakan kepercayaan seseorang kepada lembaga penyedia jasa dapat diukur melalui 3 (tiga) indikator yaitu: kredibilitas, kompetensi dan sikap moral. Kredibilitas berhubungan dengan penilaian muzakki bahwa penyedia jasa (lembaga zakat) dapat dipercaya. Adapun kompetensi menunjukkan keterampilan dan pengetahuan amil zakat untuk melakukan pelayanan yang diharapkan oleh muzakki. Sedangkan sikap moral yaitu sikap para amil di lembaga zakat terhadap muzakki.

\section{METODE PENELITIAN}

Penelitian ini menggunakan metode deskriptif kuantitatif untuk menganalisis tingkat kepercayaan muzakki kepada Baitul Mal Aceh. Populasi yaitu para muzakki yang menjadi pembayar zakat di Baitul Mal Aceh pada tahun 2018 sejumlah 22.342 orang. Disebabkan populasi terlalu besar, maka diambil sampel sebanyak 100 muzakki dari hasil perhitungan ukuran sampel menggunakan rumus Slovin. Teknik pengambilan sampel menggunakan persampelan acak sederhana.

Data diperoleh dari jawaban responden pada kuesioner yang dibagikan kepada pra muzakki. Jenis kuesioner yang digunakan yaitu kuesioner tertutup, yaitu kuesioner yang menyediakan pilihan jawaban bagi responden dalam bentuk skala likert, yaitu Sangat Setuju (SS) skor 5, Setuju (S) skor 4, Cukup Setuju (CS) skor 3, Tidak Setuju (TS) skor 2, dan Sangat Tidak Setuju (STS) skor 1.

Uji validitas dan reliabilitas dilakukan untuk mengetahui kualitas instrumen. Menurut Sugiyono (2014), uji validitas untuk mengetahui instrumen tersebut dapat 
digunakan untuk mengukur apa yang seharusnya diukur. Sedangkan uji reliabilitas dilakukan untuk mengetahui instrumen dapat dikatakan reliabel (handal).

Analisis data menggunakan uji deskriptif melalui perangkat lunak Statistical Package for Social Sciense (SPSS). Uji ini dilakukan untuk mengetahui tingkat kepercayaan muzakki kepada Baitul Mal Aceh tergolong sudah baik atau belum, dengan asumsi sebagai berikut :

1. $\mathrm{H}_{\mathrm{o}}: \mu \leq 3,40$, artinya jika diperoleh rata-rata persepsi responden (muzakki) kurang dari 3,40, maka tingkat kepercayaan muzakki kepada Baitul Mal Aceh belum baik.

2. $\mathrm{H}_{\mathrm{a}}: \mu>3,40$, artinya jika diperoleh rata-rata persepsi responden (muzakki) lebih dari 3,40, maka tingkat kepercayaan muzakki kepada Baitul Mal Aceh sudah baik.

Nilai uji deskriptif tersebut berasal dari formula kategori skala likert menjadi 5 (lima) kategori dengan interval sebesar o,80. Interval ini diperoleh dari formula:

$$
\frac{\text { skor terting gi }- \text { skor terendah }}{\text { banyaknya kategori }}=\frac{5-1}{4}=0,80
$$

Maka dihasilkan sebanyak 5 (lima) kategori penilaian skala likert sebagaimana ditampilkan pada Tabel 2 berikut ini.

Tabel 2. Kategori Penilaian Skala Likert

\begin{tabular}{ccc}
\hline No. & Skor & Nilai Persepsi Responden \\
\hline 1 & $4,21-5,00$ & Sangat Baik \\
\hline 2 & $3,41-4,20$ & Baik \\
\hline 3 & $2,61-3,40$ & Belum Baik \\
\hline 4 & $1,81-2,40$ & Tidak Baik \\
\hline 5 & $1,00-1,80$ & Sangat Tidak Baik \\
\hline
\end{tabular}

Sumber: Lind, DA. Marchal, WG. Wathen, SA (2019)

\section{HASIL DAN PEMBAHASAN}

\section{Karakteristik Responden}

Muzakki yang menjadi responden pada penelitian ini terdiri dari laki-laki berjumlah 48 orang (48\%) dan perempuan 52 orang (52\%), artinya responden didominasi oleh perempuan. Sedangkan berdasarkan usia, Muzakki dengan usia 20 sampai dengan 29 tahun berjumlah 20 orang (20 \%), usia 30 sampai 39 tahun berjumlah 33 orang ( $33 \%$ ), usia 40 sampai dengan 49 tahun berjumlah 23 orang (23 $\%$ ), usia 50 sampai dengan 59 tahun berjumlah 16 orang (16\%), dan berusia 60 
sampai dengan 69 tahun berjumlah 8 orang (8\%). Pada data usia, responden penelitian ini didominasi oleh muzakki yang berusia 30 sampai 39 tahun.

Karakteristik pendidikan terakhir responden menunjukkan bahwa muzakki yang berpendidikan terakhir SD berjumlah 3 orang (3\%), SMP 2 orang (2\%), SMA 12 orang (12\%), Diploma 12 orang (12\%), sarjana (S1) 43 orang (43\%), dan magister (S2) 20 orang (20\%). Hal ini menunjukkan bahwa responden didominasi oleh muzakki dengan pendidikan terakhir sarjana (S1) yang berjumlah 43 orang.

Berdasarkan jenis pekerjaan, jumlah muzakki yang bekerja sebagai Aparatur Sipil Negara (ASN) berjumlah 43 orang (43\%), karyawan BUMN 23 orang (23\%), pengusaha 16 orang (16\%), dosen 3 orang (3\%), dan pensiun 6 orang (6\%), sedangkan pekerja lain-lain berjumlah 9 orang (9\%). Jadi, responden penelitian ini didominasi oleh muzakki yang bekerja sebagai ASN.

Data pendapatan per-bulan responden menunjukkan bahwa muzakki yang berpendapatan perbulan antara Rp1.000.00o sampai dengan Rp2.000.00o sejumlah 5 orang (5\%), pendapatan perbulan Rp2.00o.0oo sampai dengan Rp.3.00o.0oo sebanyak 26 orang (26\%), pendapatan perbulan Rp3.000.00o sampai dengan Rp5.000.00o berjumlah 29 orang (29\%), pendapatan perbulan Rp5.000.00o sampai dengan Rp7.ooo.ooo berjumlah 23 orang (23\%), dan muzakki yang berpendapatan lebih dari sama dengan Rp7.000.0oo berjumlah 17 orang (17\%). Jadi, responden didominasi oleh muzakki dengan penghasilan perbulan Rp3.00o.ooo sampai dengan Rp5.000.000 yang berjumlah 29 orang (29\%).

\section{Hasil Uji Kualitas Instrumen}

Hasil uji validitas menunjukkan bahwa seluruh item pertanyaan dinyatakan valid karena nilai $r_{\text {hitung }}$ lebih besar daripada $r_{\text {tabel }}\left(r_{\text {hitung }}>0,1966\right)$.

Tabel 3. Hasil Uji Validitas

\begin{tabular}{|c|c|c|c|}
\hline Item & $\mathbf{r}$ hitung & $\mathbf{r}$ table & Keterangan \\
\hline 1 & 0,748 & \multirow{11}{*}{0,1966} & valid \\
\hline 2 & 0,801 & & valid \\
\hline 3 & 0,815 & & valid \\
\hline 4 & 0,835 & & valid \\
\hline 5 & 0,746 & & valid \\
\hline 6 & 0,785 & & valid \\
\hline 7 & 0,730 & & valid \\
\hline 8 & 0,720 & & valid \\
\hline 9 & 0,737 & & valid \\
\hline 10 & 0,643 & & valid \\
\hline 11 & 0,746 & & valid \\
\hline
\end{tabular}

Sumber: Data primer diolah (2019) 
Sedangkan hasil uji reliabilitas instrumen penelitian ini disajikan pada Tabel 4 berikut.

Tabel 4. Hasil Uji Reliabilitas

\begin{tabular}{lcc}
\hline \multicolumn{1}{c}{ Variabel } & Cronbach's Alpha & Keterangan \\
\hline Tingkat Kepercayaan & 0,921 & Handal \\
\hline Sumber: Data primer diolah (2019) &
\end{tabular}

Hasil uji reliabilitas untuk semua item pernyataan variabel tingkat kepercayaan menghasilkan nilai cronbach's alpha 0,921. Disebabkan nilai cronbach's alpha melebihi o,6, maka instrumen penelitian ini handal (reliabel).

\section{Tingkat Kepercayaan Muzakki kepada Baitul Mal Aceh}

Tingkat Kepercayaan dilihat dari beberapa faktor yang mempengaruhinya, dimana jika faktor-faktor tersebut terpenuhi maka Baitul Mal Aceh menjadi tepercaya. Adapun indikator dari tingkat kepercayaan muzakki terdiri dari (1) credibility (dapat dipercaya), (2) competency (kemampuan) dan (3) courtesy (sikap moral). Gambaran hasil tanggapan muzakki mengenai kepercayaan mereka kepada Baitul Mal Aceh disajikan pada Tabel 5 .

Tabel 5. Persepsi Muzakki mengenai Tingkat Kepercayaan Muzakki kepada BMA

\begin{tabular}{|c|c|c|c|c|c|c|c|}
\hline No. & Pernyataan & STS & TS & CS & $\mathbf{S}$ & SS & $\begin{array}{l}\text { Rata- } \\
\text { rata }\end{array}$ \\
\hline 1 & $\begin{array}{l}\text { Karyawan BMA bekerja mengelola } \\
\text { zakat secara profesional }\end{array}$ & $\mathrm{O}$ & 1 & 19 & 58 & 22 & 4,01 \\
\hline 2 & $\begin{array}{l}\text { Saya tidak meragukan kompetensi } \\
\text { karyawan BMA dalam menjalankan } \\
\text { pekerjaannya }\end{array}$ & O & 1 & 18 & 60 & 21 & 4,01 \\
\hline 3 & $\begin{array}{l}\text { Jika mengalami masalah dalam } \\
\text { pembayaran zakat, BMA memberi } \\
\text { tanggapan dengan baik }\end{array}$ & $\mathrm{O}$ & 2 & 17 & 61 & 20 & 3,99 \\
\hline 4 & $\begin{array}{l}\text { Saya dapat mengandalkan BMA untuk } \\
\text { mengelola zakat saya }\end{array}$ & 0 & 3 & 15 & 54 & 28 & 4,07 \\
\hline 5 & $\begin{array}{l}\text { Keberadaan BMA memiliki reputasi } \\
\text { baik oleh berbagai pihak yang } \\
\text { berkepentingan }\end{array}$ & $\mathrm{O}$ & 1 & 22 & 57 & 20 & 3,96 \\
\hline 6 & $\begin{array}{l}\text { Orang-orang yang saya kenal } \\
\text { beranggapan BMA dapat dipercaya }\end{array}$ & O & 1 & 17 & 61 & 21 & 4,02 \\
\hline 7 & $\begin{array}{l}\text { BMA dapat membantu kesulitan saya } \\
\text { dalam pembayaran zakat }\end{array}$ & 0 & 2 & 24 & 55 & 19 & 3,91 \\
\hline 8 & $\begin{array}{l}\text { Saya merasa nyaman membayar zakat } \\
\text { melalui BMA }\end{array}$ & 0 & 2 & 13 & 61 & 24 & 4,07 \\
\hline 9 & $\begin{array}{l}\text { Antara saya dan BMA memiliki } \\
\text { kedekatan emosional }\end{array}$ & 2 & 9 & 19 & 49 & 21 & 3,78 \\
\hline 10 & $\begin{array}{l}\text { Sebagai muzakki saya dapat } \\
\text { memberikan ide maupun saran } \\
\text { kepada BMA }\end{array}$ & 1 & 5 & 11 & 59 & 24 & 4,00 \\
\hline
\end{tabular}




\begin{tabular}{llcccccc}
\hline No. & Pernyataan & STS & TS & CS & S & SS & $\begin{array}{c}\text { Rata- } \\
\text { rata }\end{array}$ \\
\hline 11 & $\begin{array}{l}\text { Jika orang lain mengetahui peran } \\
\text { BMA, maka ia juga akan membayar } \\
\text { zakat di BMA }\end{array}$ & 0 & 2 & 21 & 55 & 22 & 3,97 \\
& Rata-rata \\
\hline
\end{tabular}

Sumber: Data Primer diolah (2019)

Tabel 5 menyajikan jawaban para muzakki atas pernyataan kuesioner untuk mengukur tingkat kepercayaan mereka kepada Baitul Mal Aceh. Dari seluruh pernyataan yang diajukan kepada mereka, pernyataan "Saya dapat mengandalkan Baitul Mal Aceh untuk mengelola zakat saya”, dan pernyataan "Saya merasa nyaman membayar zakat melalui Baitul Mal Aceh" memperoleh nilai rata-rata tertinggi yaitu 4,07. Sedangkan pernyataan yang menyatakan "Antara saya dengan Baitul Mal Aceh mempunyai kedekatan emosional" mendapatkan yang nilai rata-ratanya paling rendah yaitu sebesar 3,78 .

Selain itu, persepsi muzakki secara umum mengenai tingkat kepercayaan kepada Baitul Mal Aceh diperoleh nilai rata- rata sebesar 3,98. Berdasarkan skor penilaian skala likert (sebagaimana pada Tabel 2), nilai rata-rata tingkat kepercayaan muzakki ini berada dalam rentang skor 3,41-4,20 (kategori Baik). Dengan demikian, dapat dinyatakan bahwa tingkat kepercayaan muzakki kepada Baitul Mal Aceh tergolong sudah baik.

Nilai rata-rata kepercayaan muzakki diperoleh 3,98 (lebih dari 3,4). Berdasarkan nilai rata-rata ini, maka hasil penelitian ini menolak hipotesis $\mathrm{H}_{\mathrm{o}}$ yang menyatakan bahwa tingkat kepercayaan muzakki kepada Baitul Mal Aceh belum baik. Oleh karena itu, dapat diinterpetasikan bahwa walaupun Baitul Mal Aceh merupakan lembaga pengelola zakat pemerintah, namun dapat dipercaya dengan baik oleh muzakki. Di samping itu, berdasarkan hasil penelitian ini juga menolak anggapan bahwa para muzakki membayar zakat ke Baitul Mal Aceh disebabkan hanya untuk mematuhi aturan qanun (peraturan daerah).

Kepercayaan muzakki kepada Baitul Mal Aceh yang tergolong baik mencerminkan pengelolaan zakat di Baitul Mal Aceh yang sudah baik menurut persepsi muzakki. Para muzakki yang cenderung menganggap Baitul Mal sebagai lembaga yang dapat diandalkan dalam mengelola zakat dan merasa nyaman mengamanahkan zakat melalui Baitul Mal, dapat terwujud sebagai hasil sosialisasi terkait pengumpulan dan pendistribusian zakat kepada masyarakat. Hal ini wujud dari transparansi dan akuntablilitas lembaga. Pengelolaan zakat dengan mengedepankan transparansi dan akuntabilitas menjadi faktor penting meraih 
kepercayaan muzakki sebagaimana hasil penelitian Inayah (2018) dan Hasrina, Yusri dan Agusti (2018). Kepercayaan menjadi modal penting dalam meningkatkan loyalitas muzakki (Inayah, 2018).

\section{KESIMPULAN}

Tingkat kepercayaan Muzakki kepada Baitul Mal Aceh tergolong sudah baik. Para muzakki dapat dikatakan memiliki persepsi yang baik mengenai pengelolaan zakat di Baitul Mal Aceh. Ini dibuktikan dengan tingginya kecenderungan penilaian muzakki untuk mengandalkan Baitul Mal Aceh sebagai lembaga yang mengelola zakat mereka dan hal ini selanjutnya menjadikan mereka merasa nyaman untuk membayar zakat di Baitul Mal Aceh.

Walaupun muzakki telah merasa nyaman menyerahkan zakat di Baitul Mal Aceh, namun persepsi mengenai kedekatan emosional antara muzakki dan Baitul Mal Aceh sebagai cermin loyalitas muzakki dapat dinilai belum maksimal.

\section{DAFTAR PUSTAKA}

Armiadi. (2008). Zakat Produktif: Solusi Alternatif Pemberdayaan Ekonomi Umat. Banda Aceh: Arraniry Press.

Ash-Shiddieqy, MH. (2009). Pedoman Zakat. Semarang: Pustaka Rizki Putra.

Ghazali, MZ. Saad, RAJ. Wahab, MSA. (2016). A Conceptual Framework for Examining Trust towards Zakat Institution. International Journal of Economics and Financial Issues, 6(S7).

Hafidhudddin, D. (2011). Peran Strategis Organisasi Zakat dalam Menguatkan Zakat di Dunia. Jurnal Al-Infaq, 2(1)

Hasrina, CD. Yusri. Agusti Sy, DR. (2018). Pengaruh Akuntabilitas dan Transparansi Lembaga Zakat terhadap Tingkat Kepercayaan Muzakki dalam Membayar Zakat di Baitul Mal Kota Banda Aceh. Jurnal Humaniora, 2(1)

Inayah, Nurul. Zahrotul Muanisah. (2018). Hubungan Kepercayaan,Transparansi, dan Akuntabilitas terhadap Loyalitas Muzakki Pada Badan Amil Zakat (Studi Kasus di Kecamatan Tegalsari Banyuwangi). Activa: Jurnal Ekonomi Syariah, 1(2).

Lind, DA. Marchal, WG. Wathen, SA. (2019). Basics Statistics for Business and Economics (Ninth Edtion). New York: Mc.Graw Hill.

Luthfi, Hanif. (2018). Siapakah Amil Zakat?. Jakarta: Rumah Fiqih Publishing.

Mustafa, M.O.A. Mohamad, M.H.S. Adnan, M.A. (2013). Antecedents of Zakat Payers' Trust in an Emerging Zakat Sector: An Exploratory Study. Journal of Islamic Accounting and Business Research, 4(1).

Ma'fiyah. Yughi, SA. Awaluddin, T. (2018). Preferensi Muzakki dalam Memilih Membayar Zakat di Lembaga Zakat Formal. Al-Falah: Journal of Islamic Economics, 3(2). 
Nasim, Arim \& Romdhon, MRS. (2014). Pengaruh Transparansi Laporan Keuangan, Pengelolaan Zakat dan Sikap Pengelola terhadap Tingkat Kepercayaan Muzakki (Studi Kasus pada Lembaga Amil Zakat di Kota Bandung). Jurnal Riset Akuntansi dan Keuangan, 2(3).

Qanun Aceh Nomor 10 Tahun 2018

Rais, Isnawati. (2009). Muzakki dan Kriterianya dalam Tinjauan Fikih Zakat. Al-Iqtishad, 1(1).

Riyaldi, MH. (2017). Kedudukan dan Prinsip Pembagian Zakat dalam Mengatasi Permasalahan Kemiskinan (Analisis Pandangan Yusuf Qardhawi). Jurnal Perspektif Ekonomi Darussalam, 3(1).

Sugiyono. (2014). Metode Penelitian Kuantitatif, Kualitatif, dan $R$ dan D. Bandung: Penerbit Alfabeta.

Suma, MA. (2013). Tafsir Ayat Ekonomi (Teks, Terjemah dan Tafsir). Jakarta: Amzah

Yousafzai, SY. John, GP. Gordon, RF. (2003). A Proposed Model of E-Trustfor Electronic Banking. Technovation, 23.

Zainal, H. Bakar, AA. Sa'ad, RAJ. (2016). Reputation, Satisfaction of Zakat Distribution, and Service Quality as Determinant of Stakeholder Trust in Zakat Institutions. International Journal of Economics and Financial Issues, 6(S7). 